\title{
Neurons in the white matter of the adult human neocortex
}

\section{Luisa Suárez-Solá1, Francisco J. González-Delgado', Mercedes Pueyo-Morlans², O. Carolina Medina-Bolívar ${ }^{3}$, N. Carolina Hernández-Acosta ${ }^{3}$, Miriam González-Gómez ${ }^{3}$ and Gundela Meyer ${ }^{3 *}$}

Instituto de Medicina Legal, Santa Cruz de Tenerife, Spain

2 Servicio de Neurología, Hospital Universitario de Canarias, San Cristóbal de La Laguna, Spain

3 Departamento de Anatomía, Facultad de Medicina, Universidad de La Laguna, La Laguna, Tenerife, Spain

\section{Edited by:}

Kathleen S. Rockland, RIKEN Brain

Science Institute, Japan

\section{Reviewed by:}

Javier DeFelipe, Cajal Institute (CSIC),

Spain

Kathleen S. Rockland, RIKEN Brain

Science Institute, Japan

*Correspondence:

Gundela Meyer, Departamento de Anatomía, Facultad de Medicina, 38071 La Laguna, Tenerife, Spain. e-mail:gmeyer@ull.es
The white matter (WM) of the adult human neocortex contains the so-called "interstitial neurons". They are most numerous in the superficial WM underlying the cortical gyri, and decrease in density toward the deepWM. They are morphologically heterogeneous. A subgroup of interstitial neurons display pyramidal-cell like morphologies, characterized by a polarized dendritic tree with a dominant apical dendrite, and covered with a variable number of dendritic spines. In addition, a large contingent of interstitial neurons can be classified as interneurons based on their neurochemical profile as well as on morphological criteria. WM- interneurons have multipolar or bipolar shapes and express GABA and a variety of other neuronal markers, such as calbindin and calretinin, the extracellular matrix protein reelin, or neuropeptideY, somatostatin, and nitric oxide synthase. The heterogeneity of interstitial neurons may be relevant for the pathogenesis of Alzheimer disease and schizophrenia. Interstitial neurons are most prominent in human brain, and only rudimentary in the brain of non-primate mammals. These evolutionary differences have precluded adequate experimental work on this cell population, which is usually considered as a relict of the subplate, a transient compartment proper of development and without a known function in the adult brain. The primate-specific prominence of the subplate in late fetal stages points to an important role in the establishment of interstitial neurons. Neurons in the adult WM may be actively involved in coordinating inter-areal connectivity and regulation of blood flow. Further studies in primates will be needed to elucidate the developmental history, adult components and activities of this large neuronal system.

Keywords: subplate, calretinin, Tbr1, nitric oxide synthase, neuropeptide Y, schizophrenia

\section{INTRODUCTION}

In the human brain, the white matter (WM) underlying the cerebral neocortex is highly developed and occupies a much larger volume than in other mammals. Although the dominant components of the WM are the complex fiber tracts, their ensheathing myelin and supporting glia, there are also large numbers of neurons dispersed among the fibers, termed the "interstitial neurons" (IN). They are prominent in the primate $\mathrm{WM}$, and poorly developed in the rodent. The species differences may reflect a direct correlation between the size of the cortical gray matter, the amount of WM connecting the neocortex, and the number of IN.

In human, the border between gray and white matter is sharply defined at the bottom of the sulci and along the flanks of the gyri, but more difficult to delimit at the crowns or apices of the gyri, where radial fiber fascicles intermingle with radial rows of layer VIb neurons and IN seem to be continuous with neurons of layer VIb (see Von Economo and Koskinas, 1925). The highest density of IN is in the WM immediately subjacent to the gray matter, in the zone that contains the association or " $U$ " fibers of the cortical convolutions, and then gradually decreases with increasing distance from the gray matter. Very few neurons lie among the long fiber tracts in the deep WM, such as internal capsule, superior and inferior longitudinal fasciculi, or corpus callosum. However, there is no sharp boundary between the superficial WM, rich in IN, and the deep WM, where IN are sparse. There may also be regional differences in the density of IN, with lowest numbers in the visual cortex, and higher numbers in the frontal and prefrontal cortex (Meyer et al., 1992; Smiley et al., 1998).

The IN display a variety of morphologies ranging from pyramidal-like to bipolar and multipolar. They can be classified into the two main neuronal categories also present in the gray matter, namely excitatory glutamatergic cells and inhibitory GABAergic neurons. A previous Golgi study in the WM of adult human cortex (Meyer et al., 1992) revealed the presence of neurons with the morphology of pyramidal cells displaying apical and basal dendrites covered with dendritic spines, which may represent the excitatory component of the WM. The second category of IN corresponds to non-pyramidal neurons similar to those described in the gray matter. Unfortunately, there are only few studies on IN of the adult human cortex, and most experimental data stem from nonprimate brains. In the following sections, we summarize the available literature on IN and point out the limitations of generalizing nonprimate data on the primate, and specifically, the human brain.

The figures of this review were taken from our human brain material in the Department of Anatomy, University of La Laguna, which was obtained from autopsies under the supervision of the ethical committees of our institutions. 


\section{DEVELOPMENTAL ASPECTS OF INTERSTITIAL NEURONS}

IN of the cortical WM are often referred to as "subplate" cells. During development, the subplate is a transient cell compartment just below the future layers VI-II, or "cortical plate". Birthdating studies in rodents and carnivores revealed that subplate neurons are generated at the same time as Cajal-Retzius cells in the marginal zone (or future layer I), and prior to the birth of cortical plate neurons (Chun and Shatz, 1989a; Luskin and Shatz, 1985). Subplate cells perform multiple developmental functions: they extend pioneer fibers into the internal capsule and direct thalamo-cortical pathfinding, serve as transient synaptic targets for thalamocortical fibers, and provide a substantial glutamatergic input into the maturing cortical plate, helping in the establishment of ocular dominance columns in the primary visual cortex (reviewed by Allendoerfer and Shatz, 1994; Finney et al., 1998; Friauf et al., 1990; Kanold and Shatz, 2006; Kanold et al., 2003; McConnell et al., 1989). As the cortical plate matures, many subplate neurons degenerate and undergo programmed cell death (Allendoerfer and Shatz, 1994; Kostovic and Rakic, 1990; Wahle and Meyer, 1987). The survivors continue into adult life as IN of the WM (Chun and Shatz, 1989b; Kostovic and Rakic, 1980, 1990).

Subplate neurons are morphologically and neurochemically heterogeneous. The GABAergic subpopulations may express a variety of peptides such as neuropepide $Y$, somatostatin and cholecystokinin, or contain nitric oxide synthase (Chun and Shatz, 1989a; Finney et al., 1998; Judas et al., 1999; Meyer et al., 1992; TorresReveron and Friedlander, 2007; Uylings and Delalle, 1997; Wahle and Meyer, 1987; Wahle et al., 1987). It is not known if developmental cell death affects specific cell classes within the subplate, or whether all subpopulations are equally reduced.

To what extent is the subplate of rodents and carnivores comparable to the human subplate? In human fetuses, an initial cell condensation, the "pioneer plate", appears at 7/8 gestational weeks (GW) and is almost immediately split into superficial and deep pioneer neurons by the arrival of the first cortical plate cohorts at 8/9 GW (Meyer et al., 2000). The deep pioneer cells form the "presubplate" (Kostovic and Rakic, 1990; Meyer et al., 2000). The subplate zone proper becomes visible around 14/15 GW as a cellpoor/fiber-rich layer situated between the intermediate zone and the cortical plate. It reaches maximal width and highest cellularity from 22-36 GW, when it is four times thicker than the cortical plate. Thereafter, the subplate gradually decreases in size and becomes unrecognizable around the sixth postnatal month (Kostovic and Rakic, 1990). NPY-immunoreactive neurons attributed to the subplate appear around $14 \mathrm{GW}$ in the subplate and decrease in number by the end of gestation (Bayatti et al., 2008; Uylings and Delalle, 1997). A similar time course of subplate development has been described in the monkey (Smart et al., 2002), showing that the subplate develops differently in nonprimate and primate species.

Although human subplate neurons are heterogeneous, a useful marker of the glutamatergic component is the putative transcription factor T-brain-1 (Tbr1) (Bayatti et al., 2008; Hevner et al., 2001; Kolk et al., 2005). The chronology of Tbr1 expression in human fetuses can be traced to the early cortical plate at $10 \mathrm{GW}$, which is strongly Tbr1+ (Figure 1A). From 14 to 25 GW, large numbers of Tbr1+ neurons are continuously added to the subplate compartment, which increases in width concurrent with the growth of the

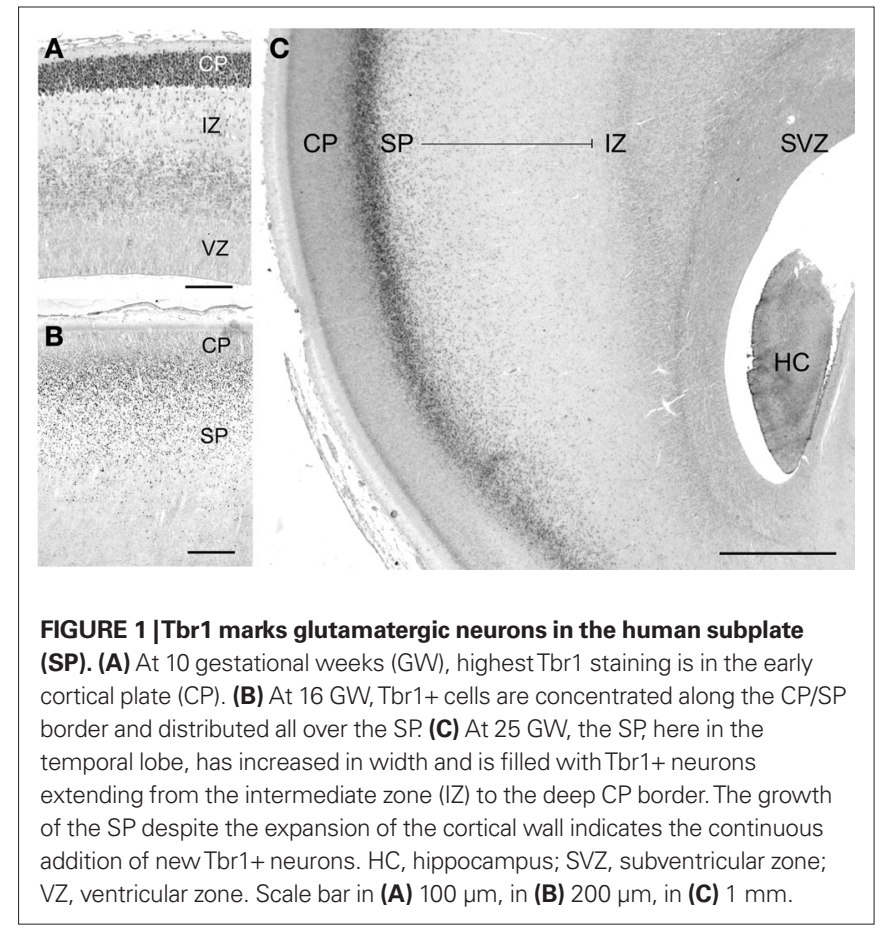

cortical plate, although the highest density is always at the border between cortical plate and subplate (Figures 1B,C) (Meyer, 2007). In perinatal brains, Tbr1-immunoreactivity changes from a nuclear to a cytoplasmic staining that is widely distributed in neurons in the cortical gray and white matter, and thus no longer useful as a marker molecule of the subplate. In the absence of molecules specific for the human subplate it is difficult to ascertain how many subplate cells survive as IN.

Altogether, these data show that the IN of the human WM are not identical to the early-born subplate neurons described in rodents and cat. Rather, the cell populations in the maturing WM seem to be complemented by newly arriving neurons generated at much later stages of corticogenesis. A possible explanation for the discrepancy across species may be the extraordinary increase in cortical connectivity during evolution, which leads to an increase in size and complexity of the WM in the primate brain. In parallel to the increase of the WM compartment, a continuous supply of IN may be required during the whole period of corticogenesis. This implies that primate IN are not just incidental remnants of early-born neurons, but rather seem to belong to a distinct neuronal system that is intimately connected to the WM and may carry out activities pertinent to this location. Further studies are necessary to define the developmental origins and possible functions of IN in the adult WM of the primate cortex.

\section{CALCIUM-BINDING PROTEINS IN INTERSTITIAL NEURONS}

The GABAergic interneurons of the cortical gray matter are highly diverse, and many attempts have been undertaken to classify them according to a variety of morphological and neurochemical properties (Ascoli et al., 2008). A recent inventory of mouse cortical interneurons has led to the identification of 13 cell classes based on the combined expression of the calcium-binding proteins calbindin $(\mathrm{CB})$, calretinin $(\mathrm{CR})$ and parvalbumin $(\mathrm{PV})$, and neuropetides, 
such as vasointestinal polypeptide, NPY, cholecystokinin, somatostatin and cholinacetyltransferase (Gonchar et al., 2008). Of the three calcium-binding proteins present in the cortical gray matter, only CB and CR are expressed in IN. PV+ cells are the largest group of cortical interneurons which includes basket cells and chandelier cells (De Felipe, 2002). PV is not found in the adult human WM, and the few deep PV+ neurons occasionally found below the gray matter are more likely to represent displaced layer VI neurons. CB+ IN have been reported in the WM (Yan et al., 1996); they are concentrated in the superficial WM, often aligned along the gray/WM border and most numerous in the apex regions. They are small to medium size, have bipolar or multipolar dendritic trees (Figures 2C,D), and are rare in the deep WM.

$\mathrm{CR}$ is abundant in gray-matter interneurons mostly of supragranular layers (Gonchar et al., 2008), but its presence in the WM has not attracted much attention. This is surprising insofar as CR+ IN are the most prominent cell population in the superficial and deep adult human WM (Figures $2 \mathrm{~A}$ and 3 ). They have diverse sizes, ranging from small to large somata, and bipolar or multipolar dendritic trees, regardless of their position in the superficial or deep WM. Small CR+ IN occur also in the internal capsule, and even in the periventricular WM of the temporal horn of the lateral ventricle. Here they form conspicuous cell clusters that give rise to local plexuses of varicose fibers, which often surround blood vessels or follow the vascular wall (Figures 3A,B). The small, dense fiber plexus, mostly restricted to the cluster and with few fibers spreading into the adjacent WM, suggests synaptic contacts between neighboring cells (Figure 3C). This staining was not observed with other markers and seems to be unique to CR.
The distribution and relative prominence of interneurons expressing calcium-binding proteins are species and area-dependent (Hof and Sherwood, 2005). CR+ cells seem to be more prominent in primate than in rodent cortex, not only in the gray matter but also in the WM. In the mouse, $\mathrm{CR}+$ interneurons derive from the caudal ganglionic eminence and migrate tangentially all over the cortex (Xu et al., 2004). By contrast, primate interneurons have a double origin, with early-born cells migrating from ganglionic eminences, and later-born cells deriving from the subventricular zone (SVZ) of the cortical wall (Letinic et al., 2002; Petanjek et al., 2009). In particular, CR+ cells are very prominent in the SVZ and deep WM during late human fetal development. Characteristic clusters of doublecortin/CR+ neurons in the SVZ were interpreted as locally born interneurons destined for the superficial cortical layers (Meyer et al., 2002). The CR+ cell clusters in the adult WM suggest that not all of these cells migrate into the gray matter but may give rise to resident cells of the WM, or stay close to their place of origin. In any case, the CR+ IN in the deep WM are not derivatives of an early generated subplate, but rather late additions at a time when the fiber fascicles of the WM mature and may need positional cues. Further studies of this cell population may be interesting, particularly with regard to neuropathological alterations.

\section{NITRIC OXIDE SYNTHASE AND NEUROPEPTIDES IN INTERSTITIAL NEURONS}

Nitric oxide (NO) is a gaseous messenger molecule synthetized by several isoforms of the enzyme nitric oxide synthase (NOS). In the brain, two NOS forms are constitutively expressed, nNOS in neurons, and eNOS in endothelial cells. Activation of nNOS and
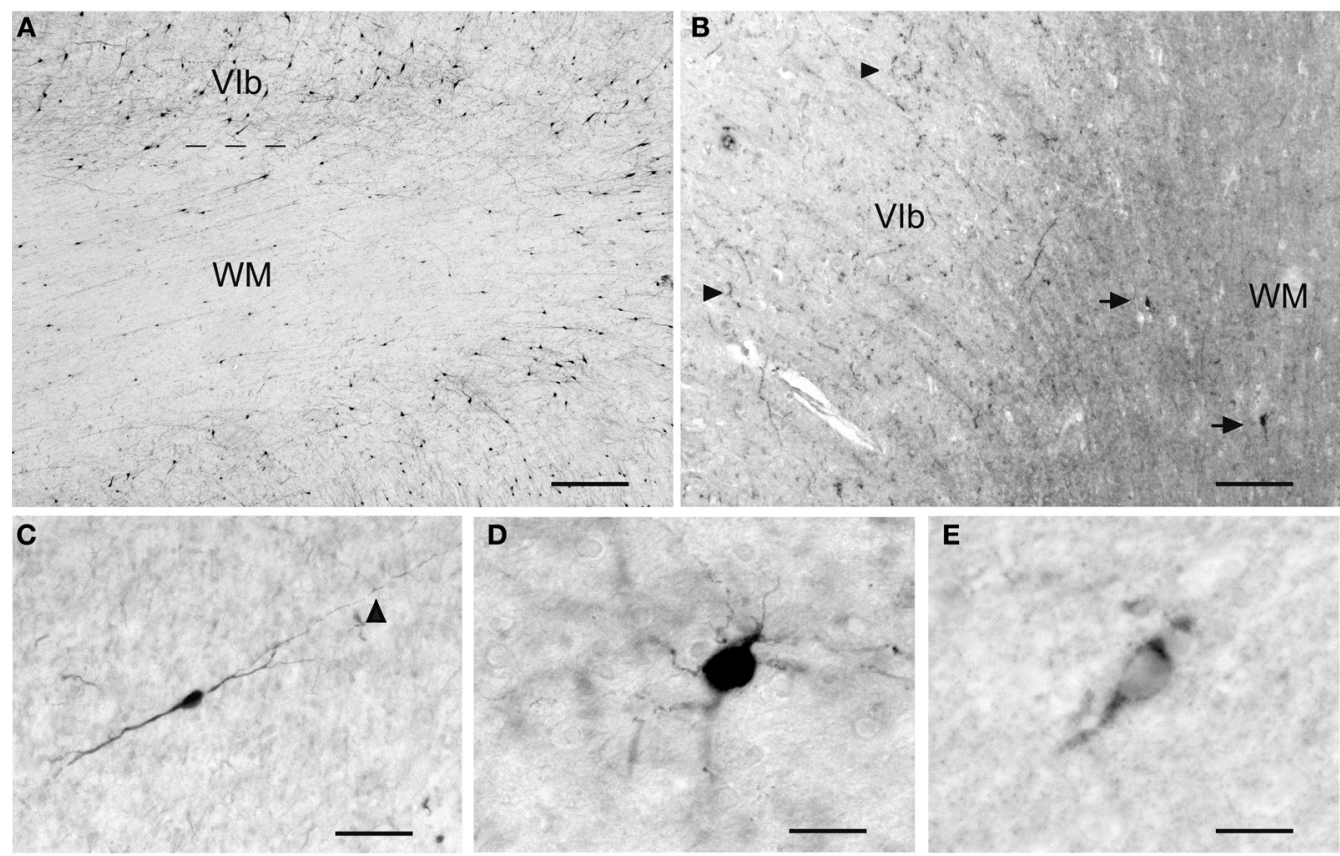

FIGURE 2 |The variety of IN in the adult human WM. (A) $C R+I N$ are the most abundant cell class in the superficial WM. (B) NPY+ IN (arrows) in the superficial WM. They may be the origin of the fiber terminals in layer VI, indicated by arrowheads. (C) A bipolar CB+ IN in the deep WM.
The arrowhead points to an axonal ramification site. (D) A multipolar $\mathrm{CB}+\mathrm{IN}$ in the superficial WM. (E) A Reelin+ IN in the superficial WM. Scale bar in (A) $200 \mu \mathrm{m}$, in (B) $150 \mu \mathrm{m}$, in (C) $30 \mu \mathrm{m}$, in (D) $20 \mu \mathrm{m}$, in (E) $15 \mu \mathrm{m}$. 


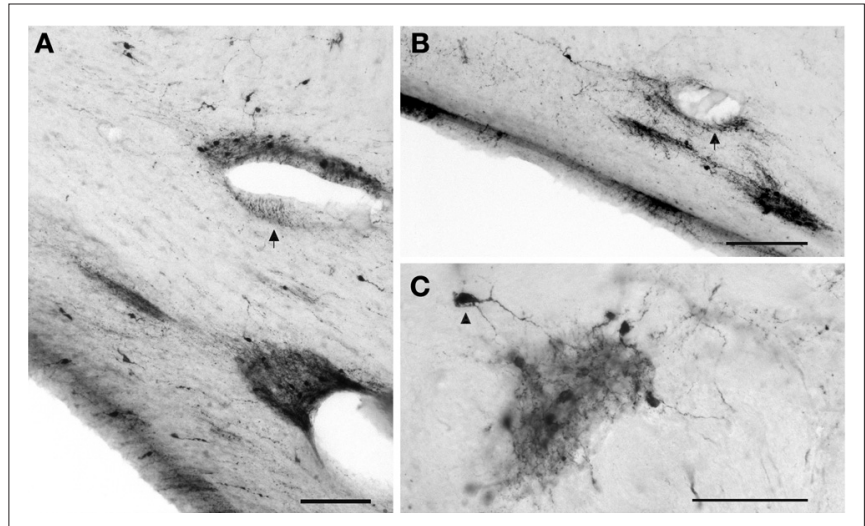

FIGURE 3 | CR+ neurons in the deep WM of the temporal lobe. (A,B) Clusters of small neurons are concentrated near blood vessels. The arrows point to fibers running along the vascular wall. (C) Cluster in the deepWM. The dense local axonal plexus is mostly confined to the cluster, with few fibers extending into the neighboring WM. The arrowhead points to an axon contacting a soma. Scale bar in (A) $50 \mu \mathrm{m}$, in (B) $100 \mu \mathrm{m}$, in (C) $50 \mu \mathrm{m}$

eNOS requires the influx of calcium ions, usually upon the activation of glutamate NMDA-receptors, and the presence of nicotinamide adenine dinucleotide phosphate (NADPH) as a co-substrate. Nitrergic, i.e. NO-producing neurons, can be visualized by NADPHdiaphorase histochemistry, as well as by immunohistochemistry using anti-nNOS antibodies (Bredt et al., 1991; Estrada and De Felipe, 1998; Hope et al., 1991; Vincent and Kimura, 1992). Due to its high diffusibility and short half-life, NO is associated with many diverse functions, such as cerebrovascular coupling, neurotransmission, neuronal survival and death, memory, and synaptic plasticity (reviewed by Calabrese et al., 2007; Garthwaite, 2008).

NADPH-d neurons in the cerebral cortex have been studied extensively in a variety of species from rodent to human (Barone and Kennedy, 2000; Estrada and De Felipe, 1998; Garbossa et al., 2005; Judas et al., 1999; Smiley et al., 1998; Yan et al., 1996). There are two main cell classes: Type $1 \mathrm{NADPH}-\mathrm{d}$ neurons are intensely stained in a Golgi-like fashion, displaying medium size to large somata and long varicose processes (Figure 4A). Most type 1 neurons are in the superficial WM, whereas type $2 \mathrm{NADPH}-\mathrm{d}$ neurons are restricted to the cortical gray matter. Type 2 neurons are only lightly stained and have small somata and short processes (Barone and Kennedy, 2000; Sandell, 1986). Both types express GABA, and a $4 \%$ of type 1 neurons co-express CB (Yan et al., 1996). Type 1 neurons can also express neuropeptide Y (Figure 2B) and somatostatin (Vincent et al., 1983). Although most GABAergic neurons are interneurons with local axons, some NADPH-d/nNOS+ neurons in the WM of rat, cat and monkey project over long distances to distant, functionally unrelated cortical areas (Higo et al., 2007; Meyer et al., 1991; Tomioka and Rockland, 2007).

One of the most interesting features of the type 1 neurons is their close association with blood vessels. Their axonal plexuses form a dense network around microvessels (Figure 4B), and their long processes may contact distant arterioles and capillaries (Estrada and De Felipe, 1998; Estrada et al., 1993; Iadecola et al., 1993; Yan et al., 1996). Since NO is a potent vasodilator, NOS-containing neurons are thought to be involved in the coupling of metabolic

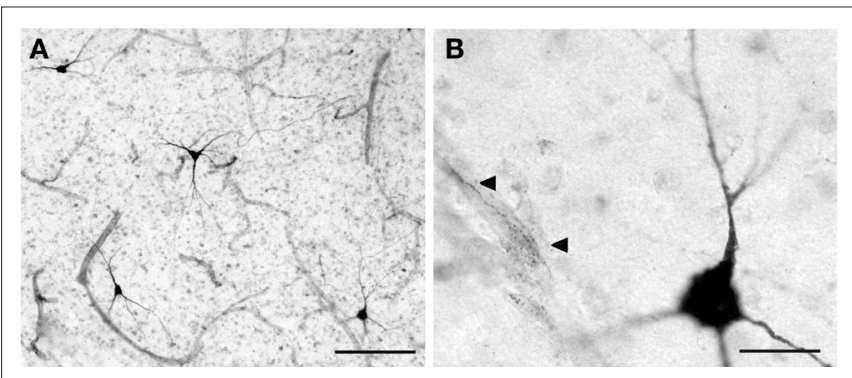

FIGURE 4 | (A)Type 1 NADPH-d+neurons in the superficial WM. (B) Magnified view of a type 1 neuron near a microvessel that is contacted by NADPH-d+axonal fibers (arrowheads). Scale bar in (A) $150 \mu \mathrm{m}$; in (B) $20 \mu \mathrm{m}$.

changes related to neuronal function with local increases in blood flow. Due to their strategic location just below the cortical gray matter, NOS+ IN may be contacted by corticopetal fibers and, in response, act on neighboring microvessels. On the other hand, NPY is a powerful vasoconstrictor able to antagonize the vasodilating effect of NO (Abounader and Hamel, 1997; Cauli et al., 2004) that co-localizes with NOS in a subset of IN. Somatostatin and NPY (Figure 3B) are expressed in IN of the superficial WM. They act directly on smooth muscle cells of cortical arterioles, and may thus constrict cortical microvessels in an activity-dependent manner (Cauli et al., 2004). A possible mechanism of the combined activity of NO and NPY in the same neuron has been proposed by Estrada and De Felipe (1998): A stimulated type 1 NADPH-d+ neuron might release NO in a diffuse way in the vicinity of the soma and main processes and increase local flow, whereas axonal branches of the same neurons ramify around more distant microvessels and release NPY, producing a spatially restricted vasoconstriction. The NOS/NPY+ IN thus form part of the neural system involved in the coupling of cortical microvessels to neuronal activity. The neurovascular interactions leading to the hemodynamic changes during enhanced or decreased cortical activity are the basis of functional neuroimaging using positron-emission tomography (PET) and functional magnetic resonance imaging ( $\mathrm{fMRI}$ ). The blood oxygen level-dependent (BOLD) signal reflects the hemodynamic response coupled to neural signalling processes (for review, see Attwell and Iadecola, 2002; Logothetis and Wandell, 2004; Ogawa et al., 1990). The NOS+ IN in the cortical WM are an important component of the vasoactive pathways which also include subcortical cholinergic and serotoninergic systems. In fact, most NOS-expressing IN are cholinoceptive, meaning that they receive cholinergic fibers from the nucleus basalis (Kocharyan et al., 2008; Smiley et al., 1998). Since the axons of NOS+ IN may spread over considerable distances into the cortical gray matter, a single IN may coordinate local blood flow in neighboring and distant cortical areas in response to corticopetal and corticofugal activation.

\section{INTERSTITIAL NEURONS IN BRAIN PATHOLOGY}

The subcortical WM and its resident IN have been associated with a variety of neurological and psychiatric disorders. Alterations of somatostatin, NPY and/or NADPH-d+ IN were observed in Alzheimer disease (e.g. Kowall and Beal, 1988; Tao et al., 1999; Van de Nes et al., 2002). However, schizophrenia is the disease 
which seems to show the most dramatic abnormalities of the WM. Diffusion tensor imaging revealed disturbances of myelin function and distribution, alterations of connectivity and integrity of fiber tracts such as the cingulate bundle and uncinate fasciculus, with a higher incidence in the frontal lobes, middle temporal structures including hippocampus and amygdala, and superior temporal gyrus, as well as in subcortical centers (reviewed by Kubicki et al., 2007; Kyriakopoulos et al., 2008).

Schizophrenia also affects the IN in diverse ways. In the frontal lobe of schizophrenic patients, the IN density was decreased in the superficial WM, but increased in the deeper WM, with NADPH-d+ IN showing the same maldistribution as microtubule associated protein 2 (MAP2) positive cells in general (Akbarian et al., 1993, 1996). While some studies reported an increase in IN density in inferior parietal and dorsolateral prefrontal areas in deficit syndrome patients (Kirkpatrick et al., 1999, 2003), others observed no change neither in superficial nor in deep white matter (Beasley et al., 2002). The conflicting reports on the changes of IN density in schizophrenia were summarized by Eastwood and Harrison (2005), who observed a density increase in the superficial WM and no change in deeper compartments.

A special and rather minor subclass of IN expresses the extracellular matrix molecule Reelin, which is important for brain development and adult neuronal plasticity (reviewed by Herz and Chen, 2006; Tissir and Goffinet, 2003). In the adult cortical gray matter, Reelin is expressed by a subgroup of GABAergic interneurons (Pesold et al., 1998); in the WM, very few scattered Reelin+ cells can be visualized using immunohistochemistry (Figure 2E). Conversely, Reelin mRNA has been reported to be abundant in IN in the superior temporal cortex, and to be significantly reduced in schizophrenic patients (Eastwood and Harrison, 2003), in keeping with the finding that alterations of Reelin expression are a putative vulnerability factor in schizophrenia and mood disorders (reviewed by Fatemi et al., 2008).

Most discussions of IN changes in psychoses are based on the view that IN are remnants of the early-born subplate population. The early generation of IN in rodents and carnivores, and their maldistribution in schizophrenic patients, have led to the hypothesis that a migration defect of the subplate during embryonic or early fetal development underlies the pathogenesis of schizophrenia. As stated above, the developmental history of the subplate is very different in nonprimate mammals and in primates including human (Kostovic and Rakic, 1980; Meyer, 2007; Meyer et al., 2000; Smart et al., 2002). An important task for future research would be a molecular taxonomy of all neuronal populations in the WM, similar to the work done on interneurons in the gray matter. It would be particularly important to differentiate between early-born components, probably related to transient roles of the subplate, and later-appearing resident cells, which may not be important for development but rather involved in activities proper to the adult WM. The recent discovery of subplate-specific molecules in mice (Hoerder-Suabedissen et al., 2008) is a useful step in this direction, and it is hoped that similar work will shed light on the origins, categories and functional roles of human IN.

\section{ACKNOWLEDGEMENT}

This work has been supported by a grant from the Fundación Canaria de Investigación y Salud (PI 57/07).

\section{REFERENCES}

Abounader, R., and Hamel, E. (1997). Associations between neuropeptide Y nerve terminals and intraparenchymal microvessels in rat and human cerebral cortex. J. Comp. Neurol. 388, 444-453.

Akbarian, S., Bunney, W. E., Potkin, S. G., Wigal, S. B., Hagman, J. O., Sandman, C.A., and Jones, E. G. (1993). Altered distribution of nicotinamide-adenine dinucleotide phosphate-diaphorase cells in frontal lobe of schizophrenics implies disturbances of cortical development. Arch. Gen. Psychiatry 50, 169-177.

Akbarian, S., Kim, J. J., Potkin, S. G., Hetrick, W. P., Bunney, W. E., and Jones, E. G. (1996). Maldistribution of interstitial neurons in prefrontal white matter of the brains of schizophrenic patients. Arch. Gen. Psychiatry 53, 425-436.

Allendoerfer, K. L., and Shatz, C. J. (1994). The subplate, a transient neocortical structure, its role in the development of connections between thalamus and cortex. Annu. Rev. Neurosci. 17, 185-218.

Ascoli, G. A., Alonso-Nanclares, L., Anderson, S. A., Barrionuevo, G.,
Benavides-Piccione, R., Burkhalter, A., Buzsáki, G., Cauli, B., Defelipe, J., Fairén, A., Feldmeyer, D., Fishell, G., Fregnac, Y., Freund, T. F., Gardner, D., Gardner, E. P., Goldberg, J. H., Helmstaedter, M., Hestrin, S., Karube, F., Kisvárday, Z. F., Lambolez, B., Lewis, D. A., Marin, O., Markram, H., Muñoz, A., Packer, A., Petersen, C. C., Rockland, K. S., Rossier, J., Rudy, B., Somogyi, P., Staiger, J.F., Tamas, G., Thomson, A. M., Toledo-Rodriguez, M., Wang, Y., West, D. C., Yuste, R. (2008). Petilla terminology, nomenclature of features of GABAergic interneurons of the cerebral cortex. Nat. Rev. Neurosci. $9,557-568$.

Attwell, D., and Iadecola, C. (2002). The neural basis of functional brain imaging signals. Trends Neurosci. 25, 621-625.

Barone, P., and Kennedy, H. (2000). Non-uniformity of neocortex, areal heterogeneity of NADPH-diaphorase reactive neurons in adult macaque monkeys. Cereb. Cortex 10, 160-174.

Bayatti, N., Moss, J. A., Sun, L., Ambrose, P., Ward, J. F., Lindsay, S., and Clowry, G. J. (2008). A molecular neuroanatomical study of the developing human neocortex from 8 to 17 postconceptional weeks revealing the early differentiation of the subplate and subventricular zone. Cereb. Cortex 18, 1536-1548.

Beasley, C. L., Cotter, D. R., and Everall, I. P. (2002). Density and distribution of white matter neurons in schizophrenia, bipolar disorder and major depressive disorder, no evidence for abnormalities of neuronal migration. Mol. Psychiatry 7, 564-570.

Bredt, D. S., Glatt, C. E., Hwang, P. M., Fotuhi, M., Dawson, T. M., and Snyder, S. H. (1991). Nitric oxide synthase protein and mRNA are discretely localized in neuronal populations of the mammalian CNS together with NADPH diaphorase. Neuron 4, 615-624.

Calabrese, V., Mancuso, C., Calvani, M. Rizzarelli, E., Butterfield, D. A., and Stella, A. M. (2007). Nitric oxide in the central nervous system, neuroprotection versus neurotoxicity. Nat. Rev. Neurosci. 10, 766-775.

Cauli, B., Tong, X. K., Rancillac, A., Serluca, N., Lambolez, B., Rossier, J., and Hamel, E. (2004). Cortical GABA interneurons in neurovascular cou- pling, relays for subcortical vasoactive pathways. J. Neurosci. 24, 8940-8949.

Chun, J. J., and Shatz, C. J. (1989a). The earliest-generated neurons of the cat cerebral cortex, characterization by MAP2 and neurotransmitter immunohistochemistry during fetal life. J. Neurosci. 9, 1648-1667.

Chun, J. J., and Shatz, C. J. (1989b). Interstitial cells of the adult neocortical white matter are the remnant of the early generated subplate neuron population. J. Comp. Neurol. 282, 555-569.

De Felipe, J. (2002). Cortical interneurons, from Cajal to 2001. Prog. Brain Res. $136,215-238$.

Eastwood, S. L., and Harrison, P. J. (2003). Interstitial white matter neurons express less reelin and are abnormally distributed in schizophrenia, towards an integration of molecular and morphologic aspects of the neurodevelopmental hypothesis. Mol. Psychiatry 769, 821-831.

Eastwood, S. L., and Harrison, P. J. (2005). Interstitial white matter neuron density in the dorsolateral prefrontal cortex and parahippocampal gyrus in schizophrenia. Schizophr. Res. 79, 181-188. 
Estrada, C., and De Felipe, J. (1998). Nitric oxide-producing neurons in the neocortex, morphological and functional relationship with intraparenchymal microvasculature. Cereb. Cortex 8 , 193-203.

Estrada, C., Mengual, E., and Gonzalez, C. (1993). Local NADPH-diaphorase neurons innervate pial arteries and lie close or project to intracerebral blood vessels, a possible role for nitric oxide in the regulation of cerebral blood flow. J. Cereb. Blood Flow Metab. 13, 978-984.

Fatemi, H. S., Reutiman, T. J., and Folsom, T.D. (2008). The role of reelin in etiology and treatment of psychiatric disorders. In Reelin Glycoprotein. Structure, Biology and Roles in Health and Disease, S. H. Fatemi, ed. (New York, Springer), pp. 317-339.

Finney, E. M., Stone, J. R., and Shatz, C. J. (1998). Major glutamatergic projection from subplate into visual cortex during development. J. Comp. Neurol. 398, 105-118.

Friauf, E., McConnel, S. K., and Shatz, C. J. (1990). Functional synaptic circuits in the subplate during fetal and early postnatal development of cat visual cortex. J. Neurosci. 10, 2601-2613.

Garbossa, D., Fontanella, M., Tomasi, S., Ducati, A., and Vercelli, A. (2005). Differential distribution of NADPHdiaphorase histochemistry in human cerebral cortex. Brain Res. 1034, 1-10.

Garthwaite, J. (2008). Concepts of neural nitric oxide-mediated transmission. Eur. J. Neurosci. 11, 2783-2802.

Gonchar, Y., Wang, Q., and Burkhalter, A. (2008). Multiple distinct subtypes of GABAergic neurons in mouse visual cortex identified by triple immunostaining. Front. Neuroanat. 1, 1-11.

Herz, J., and Chen, Y. (2006). Reelin, lipoprotein receptors and synaptic plasticity. Nat. Rev. Neurosci. 11, 850-859.

Hevner, R. F., Shi, L., Justice, N., Hsueh, Y., Sheng, M., Smiga, S., Bulfone, A., Goffinet, A. M., Campagnoni, A. T., and Rubenstein, J. L. (2001). Tbr1 regulates differentiation of the preplate and layer 6. Neuron 29, 353-366.

Higo, S., Udaka, N., and Tamamaki, N. (2007). Long-range GABAergic projection neurons in the cat neocortex. J. Comp. Neurol. 503, 421-431.

Hoerder-Suabedissen, A., Wang, W. Z., Lee, S., Davies, K. E., Goffinet, A. M., Rakic, S., Parnavelas, J., Reim, K., Nicolic, M., Paulsen, O., and Molnár, Z. (2008). Novel markers reveal subpopulations of subplate neurons in the murine cerebral cortex. Cereb. Cortex 13 [Epub ahead of print 13 November 2008].

Hof, P. R., and Sherwood, C. C. (2005). Morphomolecular neuronal phenotypes in the neocortex reflect phylogenetic relationships among certain mammalian orders. Anat. Rec. A Discov. Mol. Cell. Evol. Biol. 287, 1153-1163.

Hope, B. T., Michael, G. J., Knigge, K. M., and Vincent, S. R. (1991). Neuronal NADPH diaphorase is a nitric oxide synthase. Proc. Natl. Acad. Sci. U.S.A. 88, 2811-2914.

Iadecola, C., Beitz, A. J., Renno, W., Xu, X., Mayer, B., and Zhang, F. (1993). Nitric oxide synthase-containing neural processes on large cerebral arteries and cerebral microvessels. Brain Res. 606, 148-155.

Judas, M., Sestan, N., and Kostovic, I. (1999). Nitrinergic neurons in the developing and adult human telencephalon, transient and permanent patterns of expression in comparison to other mammals. Microsc. Res. Tech. $45,401-419$.

Kanold, P. O., Kara, P., Reid, R. C., and Shatz, C. J. (2003). Role of subplate neurons in functional maturation of visual cortical columns. Science 301, 521-525.

Kanold, P. O., and Shatz, C. J. (2006). Subplate neurons regulate maturation of cortical inhibition and outcome of ocular dominance plasticity. Neuron 51,627-638.

Kirkpatrick, B., Conley, R. C., Kakoyannis, A., Reep, R. L., and Roberts, R. C. (1999). Interstitial cells of the white matter in the inferior parietal cortex in schizophrenia: an unbiased cell-counting study. Synapse 34, 95-102.

Kirkpatrick, B., Messias, N. C., Conley, R. R., and Roberts, R. C. (2003). Interstitial cells of the white matter in the dorsolateral prefrontal cortex in deficit and nondeficit schizophrenia. J. Nerv. Ment. Dis. 191, 563-567.

Kocharyan, A., Fernandes, P., Tong, X. K., Vaucher, E., and Hamel, E. (2008). Specific subtypes of cortical GABA interneurons contribute to the neurovascular coupling response to basal forebrain stimulation. J. Cereb. Blood Flow Metab. 28, 221-231.

Kolk, S. M., Whitman, M. C., Yun, M. E., Shete, P., and Donoghue, M. J. (2005). A unique subpopulation of Tbr1expressing deep layer neurons in the developing cerebral cortex. Mol. Cell. Neurosci. 30, 538-551.

Kostovic, I., and Rakic, P. (1980). Cytology and time of origin of interstitial neurons in the white matter in infant and adult human and monkey telencephalon. J. Neurocytol. 9, 219-242.

Kostovic, I., and Rakic, P. (1990). Developmental history of the transient subplate zone in the visual and somatosensory cortex of the macaque monkey and human brain. J. Comp. Neurol. 297, 441-470.

Kowall, N. W., and Beal, M. F. (1988). Cortical somatostatin, neuropeptide $\mathrm{Y}$, and NADPH diaphorase neurons, normal anatomy and alterations in Alzheimer's disease. Ann. Neurol. 23 , 105-114.

Kubicki, M., McCarley, R., Westin, C. F., Park, H. J., Maier, S., Kikinis, R., Jolesz, F. A., and Shenton, M.E (2007). A review of diffusion tensor imaging studies in schizophrenia. J. Psychiatr. Res. 41, 15-30.

Kyriakopoulos, M., Bargiotas, T., Barker, G. J., and Frangou, S. (2008). Diffusion tensor imaging in schizophrenia. Eur. Psychiatry 23, 255-273.

Letinic, K., Zoncu, R., and Rakic, P. (2002). Origin of GABAergic neurons in the human neocortex. Nature 417 , 645-649.

Logothetis, N. K., and Wandell, B. A. (2004). Interpreting the BOLD signal. Annu. Rev. Physiol. 66, 735-769.

Luskin, M. B., and Shatz, C. J. (1985). Studies of the earliest generated cells of the cat's visual cortex, cogeneration of subplate and marginal zones. J. Neurosci. 5, 1062-1075.

McConnell, S. K., Ghosh, A., and Shatz, C. J. (1989). Subplate neurons pioneer the first axon pathway from the cerebral cortex. Science 245 978-982.

Meyer, G. (2007). Genetic control of neuronal migrations in human cortical development. Adv. Anat. Embryol. Cell Biol. 189, 1-111.

Meyer, G., Gonzalez-Hernandez, T., Galindo-Mireles, D., CastaneyraPerdomo, A., and Ferres-Torres, R. (1991). The efferent projections of neurons in the white matter of different cortical areas of the adult rat. Anat. Embryol. 184, 99-102.

Meyer, G., Perez-Garcia, C. G., and Gleeson, J. G. (2002). Selective expression of doublecortin and LIS1 in developing human cortex suggests unique modes of neuronal movement. Cereb. Cortex 12, 1225-1236.

Meyer, G., Schaaps, J. P., Moreau, L., and Goffinet, A. M. (2000). Embryonic and early fetal development of the human neocortex. J. Neurosci. 20, 1858-1868.

Meyer, G., Wahle, P., CastaneyraPerdomo, A., and Ferres-Torres, R. (1992). Morphology of neurons in the white matter of the adult human neocortex. Exp. Brain Res. 88, 204-212.

Ogawa, S., Lee, T. M., Kay, A. R., and Tank, D. W. (1990). Brain magnetic resonance imaging with contrast dependent on blood oxygenation. Proc. Natl. Acad. Sci. U.S.A. 87, 9868-9872.
Pesold, C., Impagnatiello, F., Pisu, M. G. Uzunov, D. P., Costa, E., Guidotti, A., and Caruncho, H. J. (1998). Reelin is preferentially expressed in neurons synthesizing gamma-aminobutyric acid in cortex and hippocampus of adult rats. Proc. Natl. Acad. Sci. U.S.A. 95, 3221-3226.

Petanjek, Z., Berger, B., and Esclapez, M. (2009). Origins of cortical GABAergic neurons in the cynomolgus monkey. Cereb. Cortex 19, 249-262.

Sandell, J. H. (1986). NADPH diaphorase histochemistry in the macaque striate cortex. J. Comp. Neurol. 251, 388-397.

Smart, I. H., Dehay, C., Giroud, P. Berland, M., and Kennedy, H. (2002). Unique morphological features of the proliferative zones and postmitotic compartments of the neural epithelium giving rise to striate and extrastriate cortex in the monkey. Cereb. Cortex 12, 37-53.

Smiley, J. F., Levey, A. I., and Mesulam, M. M. (1998). Infracortical interstitial cells concurrently expressing $\mathrm{m} 2$-muscarinic receptors, acetylcholinesterase and nicotinamide adenine dinucleotide phosphatediaphorase in the human and monkey cerebral cortex. Neuroscience 84 , 755-769.

Tao, Z., Van Gool, D., Lammens, M., and Dom, R. (1999). NADPH-diaphorasecontaining neurons in cortex, subcortical white matter and neostriatum are selectively spared in Alzheimer's disease. Dement. Geriatr. Cogn. Disord. $10,460-468$.

Tissir, F., and Goffinet, A. M. (2003). Reelin and brain development. Nat. Rev. Neurosci. 4, 496-505.

Tomioka, R., and Rockland, K. S. (2007). Long-distance corticocortical GABAergic neurons in the adult monkey white and gray matter. J. Comp. Neurol. 505, 526-538.

Torres-Reveron, J., and Friedlander, M. J. (2007). Properties of persistent postnatal cortical subplate neurons. J. Neurosci. 27, 9962-9974.

Uylings, H. B., and Delalle, I. (1997). Morphology of neuropeptide Y-immunoreactive neurons and fibers in human prefrontal cortex during prenatal and postnatal development. J. Comp. Neurol. 379, 523-540.

Van de Nes, J. A., Sandmann-Keil, D., and Braak, H. (2002). Interstitial cells subjacent to the entorhinal region expressing somatostatin- $28 \mathrm{immu}-$ noreactivity are susceptible to development of Alzheimer's disease-related cytoskeletal changes. Acta Neuropathol. 104, 351-356.

Vincent, S. R., and Kimura, H. (1992) Histochemical mapping of nitric oxide 
synthase in the rat brain. Neuroscience 46, 755-784.

Vincent, S. R., Johansson, O., Hökfelt, T., Skirboll, L., Elde, R. P., Terenius, L., Kimmel, J., and Goldstein, M. (1983). NADPH-diaphorase: a selective histochemical marker for striatal neurons containing both somatostatin- and avian pancreatic polypeptide (APP)like immunoreactivities. J. Comp. Neurol. 217, 252-263.

Von Economo, C., and Koskinas, G. N. (1925). Die Cytoarchitektonik der Hirnrinde des erwachsenen Menschen. Wien, Springer.

Wahle, P., and Meyer, G. (1987). Morphology and quantitative changes of transient NPY-ir neuronal populations during early postnatal development of the cat visual cortex. J. Comp. Neurol. 261, 165-192.

Wahle, P., Meyer, G., Wu, J. Y., and Albus, K. (1987). Morphology and axon terminal pattern of glutamate decarboxylase-immunoreactive cell types in the white matter of the cat occipital cortex during early postnatal development. Brain Res. 433, 53-61.

Xu, Q., Cobos, I., De La Cruz, E., Rubenstein, J. L., and Anderson, S. A. (2004). Origins of cortical interneuron subtypes. J. Neurosci. 24, 2612-2622.
Yan, X. X., Jen, L. S., and Garey, L. J. (1996). NADPH-diaphorase-positive neurons in primate cerebral cortex colocalize with GABA and calciumbinding proteins. Cereb. Cortex 6 , 524-529.

Conflict of Interest Statement: The authors declare that the research was conducted in the absence of any commercial or financial relationships that could be construed as a potential conflict of interest.

Received: 05 May 2009; paper pending published: 14 May 2009; accepted: 23 May 2009; published online: 09 June 2009.
Citation: Suárez-Solá ML, GonzálezDelgado FJ, Pueyo-Morlans M, MedinaBolivar OC, Hernández-Acosta NC, González-Gómez $M$ and Meyer G (2009) Neurons in the white matter of the adult human neocortex. Front. Neuroanat. (2009) 3:7. doi:10.3389/neuro.05.007.2009

Copyright (c) 2009 Suárez-Solá, GonzálezDelgado, Pueyo-Morlans, Medina-Bolivar, Hernández-Acosta, González-Gómez and Meyer. This is an open-access article subject to an exclusive license agreement between the authors and the Frontiers Research Foundation, which permits unrestricted use, distribution, and reproduction in any medium, provided the original authors and source are credited. 